\title{
Sexualidade na gravidez e após o parto
}

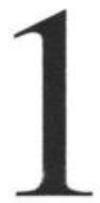

Ana Cláudia Bortolozzi Maia*

\section{RESUMO}

Muitas são as dúvidas, permeadas de crenças e mitos, sobre a prática do sexo e o exercício da sexualidade no período de gestação e após o parto, principalmente para o casal. Seria fundamental que os profissionais que trabalhassem com o tema da sexualidade estivessem mais preparados para orientar, esclarecer ou refletir sobre esta questão. O presente artigo oferece uma breve reflexão sobre a sexualidade na gravidez e após o parto, abordando as questões psicológicas mais comuns de pais e mães no período gravídico.

Primeiramente deve ser esclarecido o conceito de sexualidade. Sendo amplo, histórico e social, o conceito que temos sobre sexualidade reflete como a vivemos no nosso dia a dia (incluindo crenças, mitos e valores culturais). A grande maioria das pessoas tem presente o conceito de sexualidade relacionado exclusivamente à genitalidade, mas devemos lembrar que

* Psicóloga clínica. Professora Mestre do Curso de Psicologia, lotada junto ao Departamento de Psicologia da UNESP/Campus Bauru-SP. 
e tende a sentir-se realizada em sua feminilidade, aceitando melhor a nova condição de mulher grávida. Em geral, é comum o aumento do desejo sexual e das respostas físicas (há maior vasocongestão e intumescimento pélvico generalizado que ajuda a lubrificação e capacidade do orgasmo). Em relação ao parceiro, a mulher pode parecer mais bela (silhueta mais cheia e redonda, seios fartos, cabelos mais sedosos, ausência de menstruação, melhor lubrificação vaginal, pele mais bonita, etc.) oferecendo novos atrativos sexuais e favorecendo o desejo mútuo de manter relações sexuais;

c) Terceiro trimestre: período de maior ansiedade e desconforto geral para a mulher. É comum a diminuição do desejo e da frequiência das relações sexuais em função tanto de alterações físicas (pois a mulher já apresenta um tamanho avantajado da barriga, aumento de peso, dificuldade em arrumar uma posição confortável, aumento da fadiga), como de alterações emocionais (grande ansiedade pré-parto e, com a maternidade iminente, medo de machucar o bebê, medo de sentir orgasmo e precipitar o parto). Nesta fase é comum também o parceiro estar vivenciando a mesma ansiedade e também evitar o sexo.

Durante os nove meses de gestação, no aspecto biológico, não há perda de "desejo sexual". Tanto a mãe quanto o seu parceiro sentem "desejo de sexo", mesmo que alguns fatores envolvidos na condição da mulher grávida diminuam o desejo momentâneo da relação sexual (coito). Todos esses momentos deveriam ser vividos pelo casal com muito carinho, compreensão e diálogo. Deveríamos incentivar os casais a conversarem sobre isso entre si e com os médicos ginecologistas. As consultas do pré-natal não visam somente o bem estar do desenvolvimento físico do bebê, mas todas as condições que envolvam a vida da mulher grávida e nisto incluem-se as suas relações afetivas, as relações sexuais com o parceiro e toda a sexualidade da gestante.

\section{O SEXO DEPOIS QUE O BEBÊ NASCE}

O puerpério, palavra derivada do latim que quer dizer "ter dado à luz uma criança”, é um período de várias semanas que tem seu início imediatamente após o parto e seu término relacionado ao fato dos órgãos sexuais reprodutivos retornarem a seu estado anterior à gravidez.

As mudanças fisiológicas do puerpério são:

a) A volta do útero ao tamanho anterior: o processo de encolhimento do útero é mais rápido nas mulheres que amamentam e após 5 
ou 6 semanas o tamanho e o volume estarão novamente normais, próximos ao de uma pêra (nenhum outro órgão humano multiplica mais de 10 vezes seu tamanho e regride ao tamanho normal);

b) Descarga vaginal ou lóquios: é o sangue associado ao parto eliminado pela vagina; as mulheres podem sentir por uns três dias cólicas uterinas que são contrações dolorosas do útero, de modo irregular, em geral associadas ao ato da sucção do bebê ao mamar que faz o útero reagir contraindo-se e provocando a expulsão dos lóquios ou coágulos;

c) Retorno da menstruação: o tempo é variável entre as mulheres e se a mulher não amamenta geralmente a menstruação volta dentro de 4 a 8 semanas. Entre as que amamentam, há uma variação enorme, entre o segundo e o décimo oitavo mês, sendo a média 5 meses;

d) Aumento da micção: ocorre, em geral, entre o segundo e o quinto dia após o parto. Isso ocorre porque a mulher elimina o excesso de sangue e água acumulados durante a gestação.

Sobre o puerpério:

"É um período de rápida recuperação a reajustamento do estado de gravidez para o de não gravidez. Fisiologicamente, distingue-se por dois fenômenos notáveis: o retorno do útero ao estado não gravídico e o aparecimento do leite nos seios - apesar de ocorrer também uma série de modificações menos óbvias, como a diminuição do volume de sangue a perda do excesso de tecido líquido" (Guttmacher, 1994, p. 337).

Deve-se considerar também, neste período do puerpério, as mudanças na rotina de vida, a variação emocional da mulher em função de queda hormonal, uma possível depressão pós-parto, a lactação (e a amamentação), a perda de peso, a perda de pêlos pós-parto (queda de cabelo), a dificuldade de mobilidade (especialmente após parto cesariana), a volta gradual dos movimentos físicos mais intensos, as dietas, as cólicas uterinas, o medo de uma nova gravidez e até possíveis complicações pós-parto (como hemorragia, sangramento tardio, infecções em geral, anemia, etc.). Todos esses fatores podem ser vividos no puerpério e devem ser observados e esclarecidos ao casal, pois poderão influenciar a vida sexual e a representação da sexualidade dessa mulher e desse parceiro homem, agora "mãe" e "pai". É comum nesse período uma queda de desejo sexual da mulher por algumas semanas, evitando as relações sexuais e os contatos íntimos, mas freqüentemente há a construção de um novo patamar para a relação do casal na medida em que vão se organizando a vida familiar e conjugal.

Neste sentido, após o nascimento do bebê muitas transformações físicas, emocionais e sociais continuarão acontecendo ou se intensificarão. Al- 
guns autores, inclusive consideram o chamado puerpério como o Quarto trimestre da gestação, pois a mulher, devido ao processo da gravidez, deve lidar ainda após o parto com a reestruturação do seu esquema e imagem corporais e com o impacto da realidade da maternidade (ansiedade de perda, do vazio e do desconhecido). Todo esse contexto, segundo Noronha, Lopes \& Montgomery (1993) produz um estado de "confusão pós-parto", com intensas sensações de estranheza e ambigüidade de sentimentos que merecem ser assistidas de perto pelo médico nos três primeiros meses após o parto. Esse autores defendem a idéia de que o atendimento médico e até psicológico no puerpério deveria ser uma prática preventiva, mais no sentido de "cuidar" que "tratar", pois possibilitaria oferecer apoio emocional para toda a família, favorecendo um espaço para esclarecer, orientar, facilitar a compreensão dos conteúdos emergentes imediatamente após o parto e a longo prazo, de aprendizagem e amadurecimento que a maternidade e a paternidade exigem.

Em muitas sociedades fala-se após o parto em um "período de repouso para a mãe" que tradicionalmente era conhecido por Dieta ou Resguardo que durava um mês lunar (ou 40 a 60 dias). Durante o Resguardo a mãe deveria ficar isolada socialmente recebendo alimentação e tratamento especiais e a abstinência sexual era uma regra básica inquestionável. Hoje, com as mudanças nos costumes sociais, em boa parte devida as contribuições da medicina na recuperação da mulher após o parto, o conceito de "resguardo" mudou muito. Dificilmente uma mulher volta a trabalhar, por exemplo, ou a assumir toda uma rotina ativa socialmente dias após o parto (licença até assegurada por lei no Brasil), mas esse "afastamento das atividades sociais produtivas" não é extremo nem faz a mulher se isolar ou se "resguardar" das funções diárias que envolvem o seu dia a dia afetivo com o parceiro e com a sua família, dos cuidados gerais da casa somado aos cuidados com o bebê, com ou sem a ajuda de familiares, babás, amigos, etc. Também não implica um afastamento de sua afetividade conjugal e das relações sexuais pois, embora aconselhe-se esperar, para reassumir a relação sexual com penetração vaginal, de 4 a 6 semanas ou até que cesse o sangramento ou os órgãos reprodutores da mulher voltem ao estado normal, muitos outros contatos físicos podem e devem acontecer entre os casais que sentirem desejo.

\section{ALGUMAS DIFICULDADES EM RETORNAR À VIDA SEXUAL APÓS O PARTO E O NASCIMENTO DO BEBÊ}

- Algumas mulheres se ocupam muito com os cuidados com o bebê e acabam, física e emocionalmente, pouco disponíveis para o parceiro, inclusive no âmbito sexual; 
- Muitas mulheres se sentem pouco atraentes, com o ventre volumoso, o aumento das mamas, aumento do peso, e têm vergonha e medo de não serem desejáveis aos parceiros evitando a relação sexual;

- A amamentação pode ser desconfortável e isso pode interferir no desejo e na atividade sexual. A amamentação, assim como a gravidez, por razões culturais e educacionais, pode tornar uma mulher "dessexualizada" ou ainda a mãe pode sentir-se completa e rejeitar o marido. $\mathrm{O}$ retorno à atividade sexual (coito) é mais demorado nas mulheres que amamentam, o que pode estar associado a baixa produção de testosterona, mas, de qualquer forma, não é uma regra nem um consenso, apenas um fato a ser considerado se houver resistência em manter relações sexuais;

- Se o sexo for visto exclusivamente como função reprodutiva, a mulher que acaba de ter um filho provavelmente achará desnecessária a relação sexual. Mesmo que não seja consciente, às vezes a função reprodutiva do sexo justifica a diminuição do desejo por relações sexuais após o parto;

- Algumas frustrações ao nascimento do bebê como o sexo do bebê ser diferente do esperado, alguma malformação, alguma doença genética ou síndrome, podem ter conseqüências profundas no relacionamento do casal, inclusive no relacionamento sexual;

- O medo de uma nova gravidez é a causa mais comum do distanciamento sexual neste período. Sempre que se fizer sexo com penetração no período pós-parto é preciso prevenir-se de uma nova gravidez. A ocorrência de gravidez logo após o parto, embora muitas pessoas não acreditem, é relativamente comum (as mulheres que amamentam por períodos prolongados chegam a ficar todo o período da amamentação sem ovular, mas se houver intervalos prolongados entre a amamentação pode haver uma redução da estimulação do mamilo e os hormônios voltam ao equilíbrio normal, permitindo uma ovulação e daí uma gravidez). Prevenirse de uma gravidez indesejada neste período diminui a ansiedade e facilita o prazer nas relações sexuais; o médico poderá indicar métodos seguros de anticoncepção neste período, desde o uso de preservativos até pílulas anticoncepcionais de baixas dosagens hormonais que não interferem no aleitamento;

- A depressão pós-parto atinge muitas mulheres, principalmente nos primeiros dias após o parto, mas até mesmo meses depois. A depressão clássica, de fato reduz o interesse sexual em qualquer época da vida, para homens e mulheres. No caso da depressão pós-parto é preciso aguardar o restabelecimento hormonal e o fim da depressão, havendo necessidade do parceiro ser compreensivo e paciente. A depressão pode vir mascarada sob várias formas não 
só em comportamentos melancólicos e tristeza, mas também em comportamentos obsessivos, manias e inseguranças exageradas em relação ao bebê;

- Algumas mulheres se sentem ressentidas com o nascimento do bebê: cansam dos cuidados diários exigidos por este, além da exaustão física causada pelo parto, pelas noites de sono interrompidas. Além disso, uma eventual perda do emprego ou afastamento das relações sociais, atitudes de rejeição do parceiro em relação a ela ou ao bebê, enfim, inúmeras condições que afetam diretamente a mulher no pós-parto, podem levar a uma falta de desejo sexual como conseqüência de toda essa insatisfação;

- Eventuais dores na retomada prematura da vida sexual podem gerar associações negativas e diminuir o interesse da mulher pelo sexo. A vagina pode estar mais ressecada em virtude das alterações hormonais e possíveis cicatrizes após o parto podem ocasionar dor. Se a mulher sentir dores nas primeiras tentativas da relação sexual ela pode temer a retomada do sexo.

\section{QUANDO E COMO VOLTAR ÀS RELAÇÕES SEXUAIS?}

Não há regras e receitas para a retomada da vida sexual. O sentido da vida sexual para o casal após o nascimento do bebê espelha, na verdade, o sentido da vida conjugal e sexual anterior à gestação. Após o nascimento do bebê, é o próprio casal que deve decidir qual o momento ideal para voltar a fazer sexo; evidentemente deve-se garantir a recuperação física da mulher ao lado da retomada da intimidade do casal.

Nas primeiras semanas, mesmo sem a penetração vaginal em uma relação sexual, a intimidade sexual do casal pode ser demonstrada em beijos, carícias, masturbação, aumentando a cumplicidade e o prazer do relacionamento. Ou seja, enquanto o casal espera que a relação sexual com penetração seja possível, confortável e prazerosamente, é possível entregar-se a outros prazeres que estimulem e mantenham a intimidade, o contato corporal e o desejo mútuo. Em caso do parto normal, algumas mulheres se sentem dispostas para uma relação sexual uma ou duas semanas após o nascimento do bebê, mas em caso de parto cesariana, é recomendação médica esperar para o reinício da atividade sexual um prazo de seis semanas após o nascimento. As relações sexuais desejáveis para ambos, após o parto, não implicam em anorgasmia (falta de orgasmo) às mulheres, pois elas são capazes de sentir orgasmos e isso é bastante positivo para a recuperação pois os orgasmos, assim como a amamentação estimulam o útero a retornar ao tamanho normal.

É muito importante lembrar que nenhuma relação sexual "forçada" é prazerosa em nenhuma circunstância na vida. No puerpério, uma tentativa 
de relação sexual (pressionando o ferimento em recuperação) pode provocar eventuais dores ou desconforto tanto em mulheres que fizeram parto cesariana (devido à cirurgia) quanto nas que fizeram o parto normal (devido ao corte para a abertura da vagina - episiotomia). Essa recuperação física deve ser respeitada e compreendida pelos parceiros com atenção.

Tanto o parceiro quanto a mulher devem aguarda a "recuperação" física e emocional e não forçar a volta da relação sexual que, neste caso, pode se tornar uma experiência desastrosa. A diminuição temporária do desejo sexual não significa menor amor ou falta de atenção ao parceiro. Não seria bom as mulheres sentirem-se pressionadas - ou pelo parceiro ou por si mesmas - a resgatar o apetite sexual sem respeitar este período que é passageiro e natural. A precipitação acaba elevando à ansiedade o que prejudica a relação sexual do casal. É preciso ser paciente, diminuir as cobranças, compreender que há todo um contexto novo provocado pela chegada de um bebê que demanda atenção e cuidados quase ininterruptamente. No período pósparto, se os dois sentirem desejo um pelo outro não há nenhuma contraindicação para a relação sexual, embora essa decisão de agora em diante deva considerar todo um contexto familiar (estrutural e emocional) envolvido com a administração dos cuidados com o bebê e com a "nova" vida na casa (especialmente se for primeiro filho). Isso pode afetar tanto a mulher quanto o parceiro em relação à intensidade do desejo sexual.

$\mathrm{O}$ apoio do companheiro é fundamental. Ele deve valorizar a mulher na sua plenitude, sendo afetivo e atencioso, apesar de não ter relações sexuais. Por outro lado, a compreensão da mulher pela ansiedade e confusão também vivenciadas pelo parceiro é muito importante. $O$ diálogo, acima de tudo, é o principal caminho na resolução dos eventuais contratempos que o puerpério pode representar para o casal em relação à vida sexual. Aos poucos o casal vai retomando a vida sexual através de novas situações, novas posições, novas formas de dar e receber prazer, progressivamente até que se retorne a uma vida sexual plena e satisfatória para ambos.

\section{ALGUMAS DICAS PARA O CASAL}

- A retomada da atividade sexual após o parto é influenciada por muitos fatores físicos e emocionais. O casal deve estar consciente, esclarecido e prestar atenção aos sentimentos e necessidades um do outro. É importante dedicar-se muito ao outro, às suas necessidades, ansiedades, preocupações, alegrias, etc.;

- Depois do nascimento do bebê, é muito importante para o casal manter o contato físico carinhoso. As semanas ou até meses, depois do parto, podem ser uma fase ótima para que o casal redescubra as delícias sexuais das carícias preliminares; 
- Carícias, masturbação a dois, massagens e sexo oral são ótimas alternativas para fazer amor sem riscos e sem dor. O sexo oral é prazeroso para a mulher e também estimula o útero a voltar mais depressa ao tamanho normal;

- Se a relação sexual com penetração for ainda dolorosa, a masturbação a dois pode ser uma forma muito estimulante de prazer mútuo;

- Se a penetração profunda for dolorosa para a mulher no pós-parto, a posição conhecida como "papai-mamãe" (mulher deitada de costas e o homem deitado por cima dela) permite ao homem maior controle para fazer o sexo com delicadeza;

- As posições em que a mulher fica por cima também permitem que ela controle melhor a profundidade da penetração;

- É muito importante manter o diálogo entre o casal, buscando trocar expectativas, medos e mitos, discutir os sentimentos envolvidos na maternidade e paternidade e buscar esclarecimentos com especialistas;

- É importante que o casal procure alguém a quem possa confiar o bebê e arranje um tempo para ficar a sós, resgatando a intimidade, o clima de namoro e a atração mútua (momentos de intimidade);

- Encarar as dificuldades como "passageiras", se houver amor, compreensão e diálogo, favorece uma superação saudável para ambos.

\section{QUANDO PROCURAR AJUDA?}

Em geral as dificuldades em relação a vida sexual no período da gravidez e após o parto são compartilhadas entre os familiares ou amigos íntimos, principalmente aqueles que já passaram por esta experiência. Todas as dificuldades, normalmente, são enfrentadas pelo casal de forma gradual em que ambos vão aprendendo a lidar com a sexualidade e o sexo de uma nova forma. É preciso lembrar que a vida sexual do casal, após o nascimento do filho, sofrerá modificações, já que agora o casal deve considerar a presença de uma nova pessoa na casa e uma rotina de vida voltada para os cuidados do bebê que implica então, administrar o desejo e a espontaneidade do casal para a relação sexual e toda demanda de cuidados do bebê.

Neste sentido, diminuída a expectativa inicial do "retorno" de uma vida sexual anterior ao nascimento do filho, é possível que os casais aprendam a enfrentar os problemas cotidianos e, entre eles, as alterações da vida sexual. Porém, se após muito diálogo, tentativas de restabelecimento da ligação sexual através de massagens, masturbação, carícias, ainda assim persistir um desconforto e uma preocupação excessiva em relação ao sexo que cause sofrimento tanto para a mulher quanto para o parceiro, seria indicado 
procurar uma ajuda profissional tanto médica (que esclareça as dúvidas), quanto psicológica (que auxilie emocionalmente a passagem por estas dificuldades). $\mathrm{O}$ "grau" de sofrimento e tolerância às dificuldades é que irá indicar a necessidade de ajuda terapêutica ao casal.

\section{PALAVRAS FINAIS}

Em qualquer fase da vida a sexualidade, e nela incluída o sexo, é vivenciada com intensidade, desejos e motivações diferentes. Em nenhuma das "fases" uma forma será melhor ou pior que a outra. Os possíveis "limites” não implicam em ausência, abstinência de contato, afeto, carinho e, nas relações sexuais apenas a busca de adaptações, modificações... É assim quando a mulher fica grávida, é assim após o parto, é assim quando alguém fica doente, é assim quando alguém tem uma deficiência, é assim quando alguém atinge a terceira idade, etc. $\mathrm{O}$ importante é lembrar que a sexualidade estará sempre presente nas relações humanas e que o sexo, quando existe o amor e o desejo, será sempre possível e parte integrante da manifestação de afeto entre casais. Gerar um filho e trazê-lo ao mundo (ser mãe e pai) é uma experiência sublime no ciclo de vida das pessoas, mas ninguém deixa de ser homem e mulher, dotados dos mesmos desejos sexuais, sensualidade e beleza que cada um sabe reconhecer e corresponder quando estamos diante de alguém que amamos.

\section{REFERÊNCIAS BIBLIOGRÁFICAS}

COMFORT, A. Os prazeres do sexo. São Paulo: Martins Fontes, 1998.

DORNELLAS, D.; NEIL, M. E.; COUTO, S.; DEUTSCH, T. M. (Colaboradores e Tradutores). O guia dos amantes. São Paulo: Nova Cultural, 1996.

FENWICK, E. Guia prático mamãe \& bebê - da gravidez aos 3 anos. São Paulo: Círculo do Livro, 1995.

GUTTMACHER, A. Gravidez, nascimento e planejamento familiar. Rio de Janeiro: Bertand Brasil, 1994.

MONTGOMERY, M. Mulher, o negro do mundo - uma visão científica e humana do universo feminino. São Paulo: Gente, 1997.

NORONHA, D. T.; LOPES, G. P.; MONTGOMERY, M. Tocoginecologia psicossomática. São Paulo: Almed, 1993.

STOPPARD, M. Concepção, gravidez e nascimento. São Paulo: Globo, 1995.

SUPLICY, M. Conversando sobre sexo. Rio de Janeiro: Petrópolis, 1999. 